\title{
What are the crystallographic and genetic implications of a naturally occurring polycrystal composed of two mineral phases of distinct symmetries and anionic groups? The case study of "joint-occurrence" of emerald+alexandrite polycrystals from Brazil
}

\author{
T. Gauzzi ${ }^{1}$, L. M. Graça², M. A.L.da Silva. ${ }^{2}$, E. T. F. Freitas ${ }^{1}$, B. B. Moreira ${ }^{1}$, K. Balzuweit ${ }^{3,1}$ \\ ${ }^{1}$ Centro de Microscopia da Universidade Federal de Minas Gerais, Brazil, \\ ${ }^{2}$ Departamento de Geologia da Universidade Federal de Ouro Preto, Brazil, \\ ${ }^{3}$ Departamento de Fisica da Universidade Federal de Minas Gerais, Brazil \\ karla@fisica.ufmg.br; karlaweit@gmail.com
}

\begin{abstract}
Alexandrite and emerald are two gem-quality varieties of chrysoberyl $\left(\mathrm{BeAl}_{2} \mathrm{O}_{4}\right)$ and beryl $\left(\mathrm{Be}_{3} \mathrm{Al}_{2} \mathrm{Si}_{6} \mathrm{O}_{18}\right)$, respectively. Chrysoberyl is a multiple oxide which crystallises within orthorhombic system and space group Pmnb. Its crystalline structure is composed of $\mathrm{O}^{2-}$ anions which are distortedly arranged in a cubic closed packing together with $\mathrm{Be}^{2+}$-tetrahedra and $\mathrm{Al} 3+$ - octahedra cations; $\mathrm{Be}^{2+}$ is an inversion Citype site and $\mathrm{Al}^{3+}$ is divided into inversion Al1 (Ci-type) and reflexion Al2 (Cs-type) sites. Beryl is a cyclosilicate which crystallises within orthorhombic system and space group P6/mcc. Its crystalline structure is composed of $\mathrm{Si}^{4+}$ tetrahedra which are interconnected by their vortices, forming ring-like layers that are stacked. Between the $\mathrm{Si}^{4+}$-rings, layers of $\mathrm{Be}^{2+}$-tetrahedra and $\mathrm{Al}^{3+}$-octahedra cations are alternately arranged. Moreover, the senary axis of beryl is perpendicular to the planes formed by the stacked $\mathrm{Si}^{4+}$-rings and is parallel to the channels-like voids formed by the aforementioned rings. Chrysoberyl and beryl have been extensively studied and referred not only as gemstones (i.e. the role of $\mathrm{Cr}^{3+}$ as a chromophore element) but also as materials used to manufacture lasers. Alexandrite and emerald were simultaneously approached in few studies, although studied separately. Thus, there was no study nor reference about the "joint-occurrence" of emerald and alexandrite in just one "polycrystal". Consequently, no crystallographic relation could be established in this situation, specially all the processes that could explain the hypothetical transition from orthorhombic to hexagonal symmetry or vice versa. Two minerals that "illustrate" the crystallographic relations and the transition between the orthorhombic and hexagonal symmetries, in naturally occurring minerals, are the silicates cordierite $\left[(\mathrm{Mg}, \mathrm{Fe})_{2} \mathrm{Al}_{3}\left(\mathrm{AlSi}_{5} \mathrm{O}_{18}\right)\right.$; space group Cccm] and indialite $\left[\mathrm{Mg}_{2} \mathrm{Al}_{3}\left(\mathrm{AlSi}_{5} \mathrm{O}_{18}\right) ;\right.$ space group $\left.P 6 / m c c\right]$, respectively. The transition between these phases occurs above $1450{ }^{\circ} \mathrm{C}$ and is related to $\mathrm{Fe} /(\mathrm{Mg}+\mathrm{Fe})$ ratio during the crystallisation [1]. The transition between orthorhombic to hexagonal (no matter the order) has been mainly demonstrated by epitaxial processes which are only exemplified by synthetized materials. The phase perovskite- $\mathrm{SrIrO}_{3}$ is generally synthetized within hexagonal symmetry (space group $\mathrm{C} 2 / \mathrm{c}$ ). In conditions of high pressure, this phase symmetry becomes orthorhombic (space group Pnma) due to epitaxial processes on oxide substrates with the same crystal structure of perovskite [2]. Another example of the role of epitaxy in the transition between the aforementioned symmetries is given by multiferroics of $R \mathrm{MnO}_{3}$-type ( $R=$ rare earth elements or REE). In this case, the type of REE of $R$ site influences the symmetry: to $R=\mathrm{La}-\mathrm{Dy}$, symmetry is orthorhombic, and to $R=\mathrm{Ho}-\mathrm{Lu}$, symmetry is hexagonal. However, with the aid of epitaxial stabilization technique, orthorhombic symmetry-materials such as $\mathrm{TbMnO}_{3}, \mathrm{DyMnO}_{3}$ and $\mathrm{GdMnO}_{3}$ can be synthetized within hexagonal symmetry and originate high quality magnetic materials [3]. After contextualizing the state-of-art of the crystallographic relations and transition between orthorhombic to hexagonal symmetries, this study also proves to be novel due to the rarity of the samples: natural "jointoccurrence" alexandrite + emerald polycrystals (core of alexandrite surrounded by an emerald monocrystal) from Brazil. Apart from the transition in symmetry, other relevant questions are: how to explain the transition between a silicate (emerald) and an oxide (alexandrite), or vice versa, in the same polycrystal? Why the arrangement of the inner alexandrite monocrystals varies among the samples? Which mineral phase has crystalized first and how their genesis can be explained by chemical data? In order to answer consistently to these questions and for a better knowledge of these implications, these samples are being investigated with the aid of techniques such as electron backscattered diffraction (EBSD), transmission electron microscopy (TEM) and electronic probe microanalysis (EPMA). Preliminary TEM studies show an orientation relationship between micrometer sized grains of emerald and alexandrite.
\end{abstract}

[1] Kitamura M. \& Hiroi Y. (1982). Contributions to Mineralogy and Petrology, 80, 110-116.

[2] Bhat S.G., Gauquelin N., Sebastian N.K., Sil A., Béché A., Verbeeck J., Samal D. \& Kumar S.A. (2018). Europhysics Letters, $122,28003$.

[3] Lee D., Lee J.-H., Murugavel P., Jang S.-Y., Noh T.-W., Jo Y., Jung M.H., Ko Y.D. \& Chung J.-S. (2007). Applied Physics Letters, $90,182504$.

Keywords: Alexandrite, Emerald, Beryl, orthorhombic symmetry, hexagonal symmetry, crystallographic relationship

The authors would like to acknowledge the support of Centro de Microscopia da UFMG and CNPq, CAPES, FINEP and FAPEMIG for financial support. 